\title{
Тимофеева Н.В., Красильникова А.М. \\ Разработка интерфейса системы информационной поддержки процесса учёта средств индивидуальной защиты сотрудников предприятия
}

Северный (Арктический) федеральный университет имени М.В. Ломоносова, Институт судостроения и морской арктической техники

(Россия, Северодвинск)

doi: 10.18411/trnio-12-2021-104

\section{Аннотация}

Статья посвящена вопросу оптимизации процесса оформления и выдачи средств индивидуальной защиты. В данной работе приведен вариант разработки интерфейса системы на основе ранее подготовленного техно-рабочего проекта решения проблем, возникающих в ходе заказа, получения, выдачи и возврата средств индивидуальной защиты.

Ключевые слова: средства индивидуальной защиты, личная карточка, карточка складского учета, нормы выдачи, процессы, функциональная структура системы, интерфейс, экранная форма, печатная форма.

\section{Abstract}

The article is devoted to the issue of optimization of the process of registration and issuance of personal protective equipment. In this paper, a variant of the system interface development is given on the basis of a previously prepared techno-working project for solving problems arising during the ordering, receipt, issuance and return of personal protective equipment.

Keywords: personal protective equipment, personal card, stock control card, issuance rates, processes, functional structure of the system, interface, screen form, printed form.

В данной статье рассматривается и анализируется процесс оформления и выдачи средств индивидуальной защиты сотрудникам цеха судостроительного предприятия. Заказ и выдача СИЗ сотрудникам цеха осуществляется согласно присвоенным им профессиям [2, 3]. Основным участником процесса является кладовщик.

В конце каждого отчетного периода кладовщик формирует и передает информацию об остатках СИЗ экономисту цеха для расчета потребности СИЗ на предстоящий год и формирования соответствующей заявки. Согласно утвержденным заявкам предприятием закупаются СИЗ и передаются на склады цеха. Кладовщик цеха оформляет требования/накладные на определенные СИЗ согласно виду операции (в 2 экземплярах), подписывает экземпляры у экономиста цеха и отправляется на соответствующий склад за материалами. Все полученные СИЗ передаются в материальную кладовую (МК) цеха.

В данной кладовой ведутся карточки складского учета материалов, отдельные для каждой позиции СИЗ, причем на одну и ту же позицию могут вестись две карточки (например, по размеру, по номенклатуре и т.д.)

После получения СИЗ и постановки их на учет в МК цеха, кладовщик производит выдачу СИЗ сотрудникам цеха. На каждого сотрудника цеха оформлена личная карточка учета выдачи СИЗ. В личных карточках сотрудников уже вписаны те позиции СИЗ, которые положены им к выдаче в соответствии с их профессией. При выдаче СИЗ кладовщик руководствуется перечнем бесплатной выдачи спецодежды, спецобуви и других СИЗ для рабочих и ИТР цеха, где прописаны виды, количество и период выдачи СИЗ.

По истечении срока эксплуатации СИЗ сотрудники должны осуществить их возврат в кладовую цеха. Часто выдаваемые СИЗ, такие как респираторы, перчатки, беруши и т.д., кладовщик списывает в личной карточке учета выдачи СИЗ сотрудника без акта списания. Все остальные СИЗ (спецодежда, спецобувь) списываются только по актам списания. Все СИЗ списываются в килограммах. 
Также к оформленным актам выписываются накладные на возврат материалов из производства на утиль ватный и утиль х/б. После того как документы подготовлены (каждые в 2 экземплярах) весь утиль отправляется в другой цех предприятия [4].

Весь процесс заказа и выдачи СИЗ был проанализирован и представлен в ранее опубликованной статье в виде техно-рабочего проекта, одной из диаграмм которого является функциональная структура проектируемой системы, по пунктам которой и разработан интерфейс системы [1].

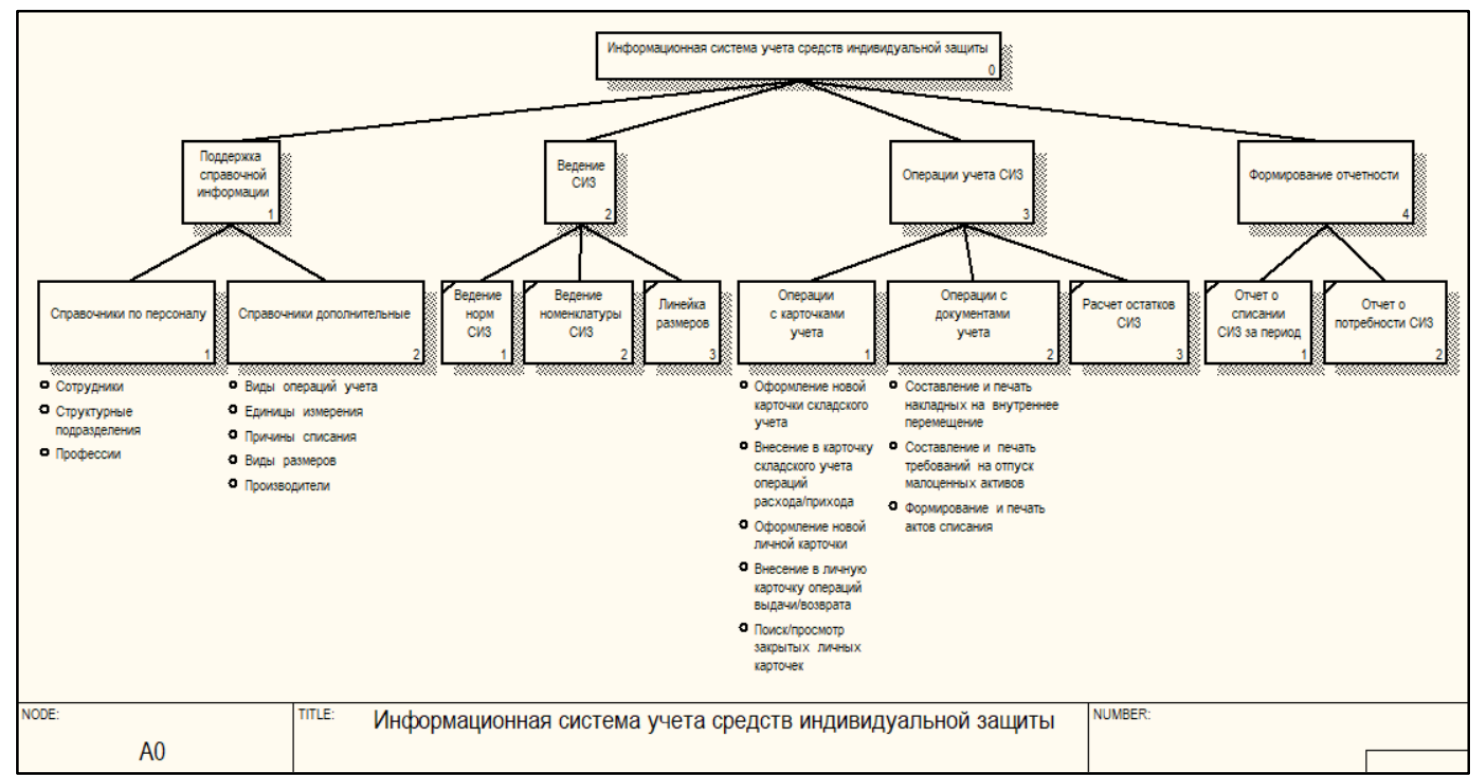

Рисунок 1. Функииональная структура системь

Функциональная структура системы предусматривает поддержку общей и дополнительной справочной информации, и информации по СИЗ, ведение операций учета СИЗ и формирование ряда отчетов.

Предполагаемая система будет иметь двухзвенную архитектуру: интерфейс системы разрабатывается в СУБД MS Access, база данных размещена на сервере MS SqlServer. C помощью технологий ODBS установлена связь таблиц сервера с экранными и печатными формами системы.

После авторизации, пользователю становится доступна главная кнопочная форма, по страницам которой осуществляется переход к необходимым операциям.

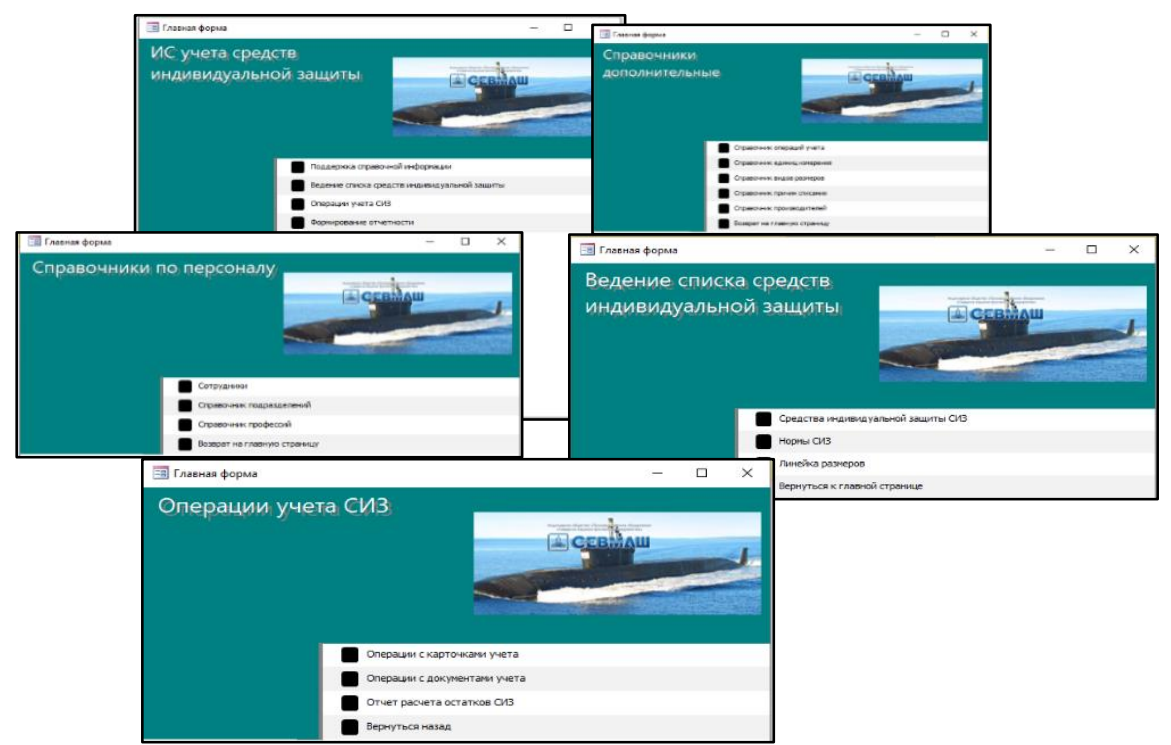

Рисунок 2. Страницьь главной кнопочной формы 
Для работы системы была произведена первоначальная загрузка данных: заполнены все справочники (основные и дополнительные) (рисунок 3) и вся информация, относящаяся к средствам индивидуальной защиты (рисунок 4).

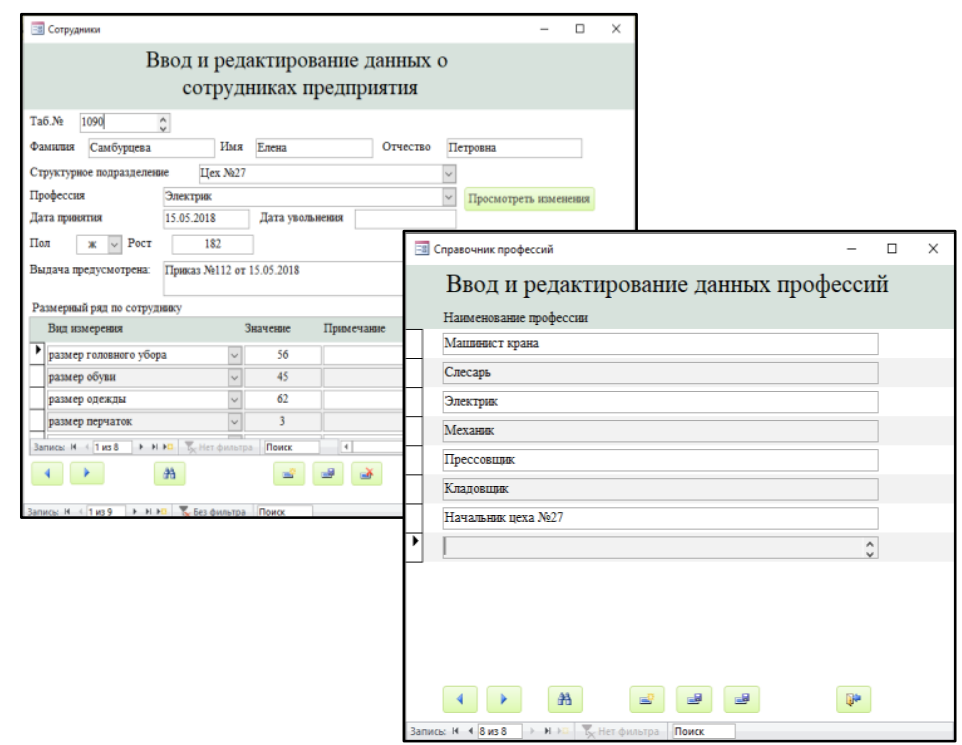

Рисунок 3. Формы основных справочников

Весь интерфейс: экранные и печатные формы разработаны в одном стиле и представляют полную возможность вставки и обработки записей.

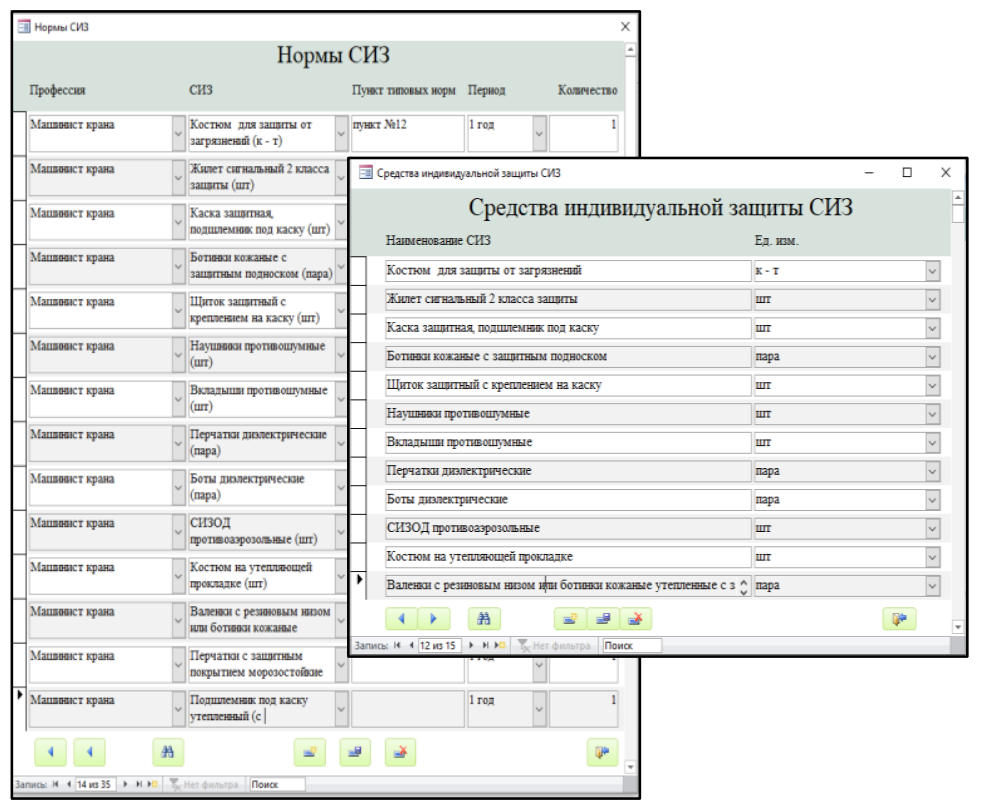

Рисунок 4. Формы ведения данных СИЗ

Для ведения основной документации: карточки складского учета, личной карточки сотрудника, требований-накладных и т.д. были проработаны и реализованы соответствующие экранные формы и печатные формы выходных документов.

На каждое средство индивидуальной защиты оформляется и ведется в течении всего срока договора поставки карточка складского учета. Данный документ является накопительной формой, так как в нее заносятся записи обо всех выданных и возвращенных экземплярах данного СИЗ. При закрытии карточки пользователю предоставляется возможность (по требованию) напечатать документ. Карточка в виде экранной и печатной формы представлена на рисунке 5. 


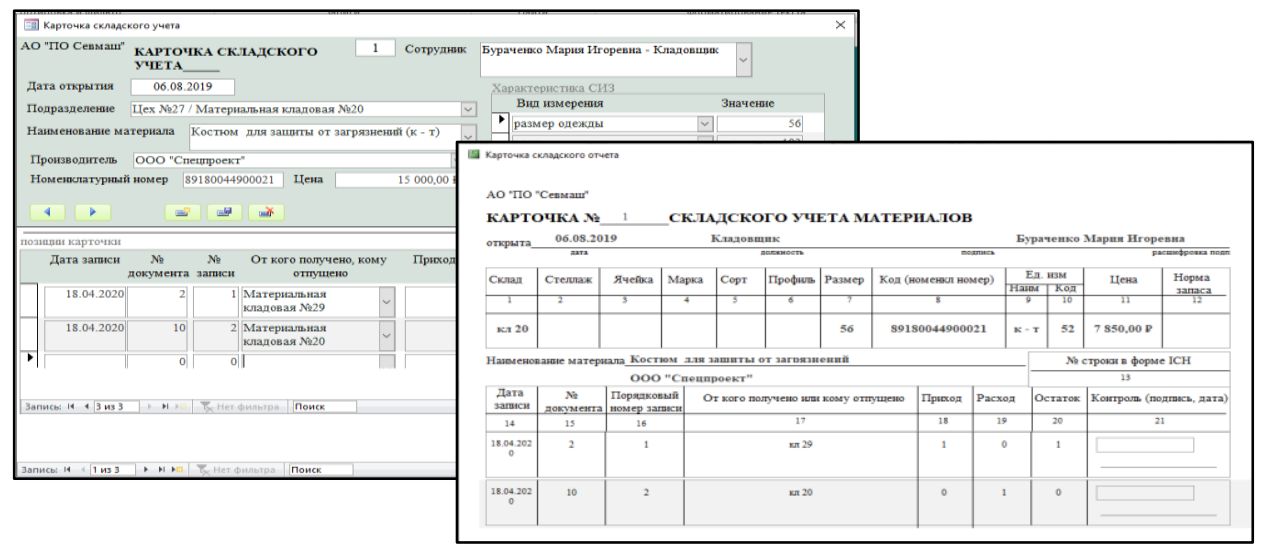

Рисунок 5. Карточка складского учета

Параллельно с внесением записей в карточку складского учета, аналогичные записи вносятся в личную карточку сотрудника, который получает и сдает СИЗ определенного размера. В личной карточке сотрудника обязательно указываются все его физиологические характеристики, что позволяет система контролировать внесение записей о СИЗ согласно указанному размеру. При оформлении карточки на нового сотрудника, в карточку системой загружаются соответствующие указанной профессии нормы СИЗ.

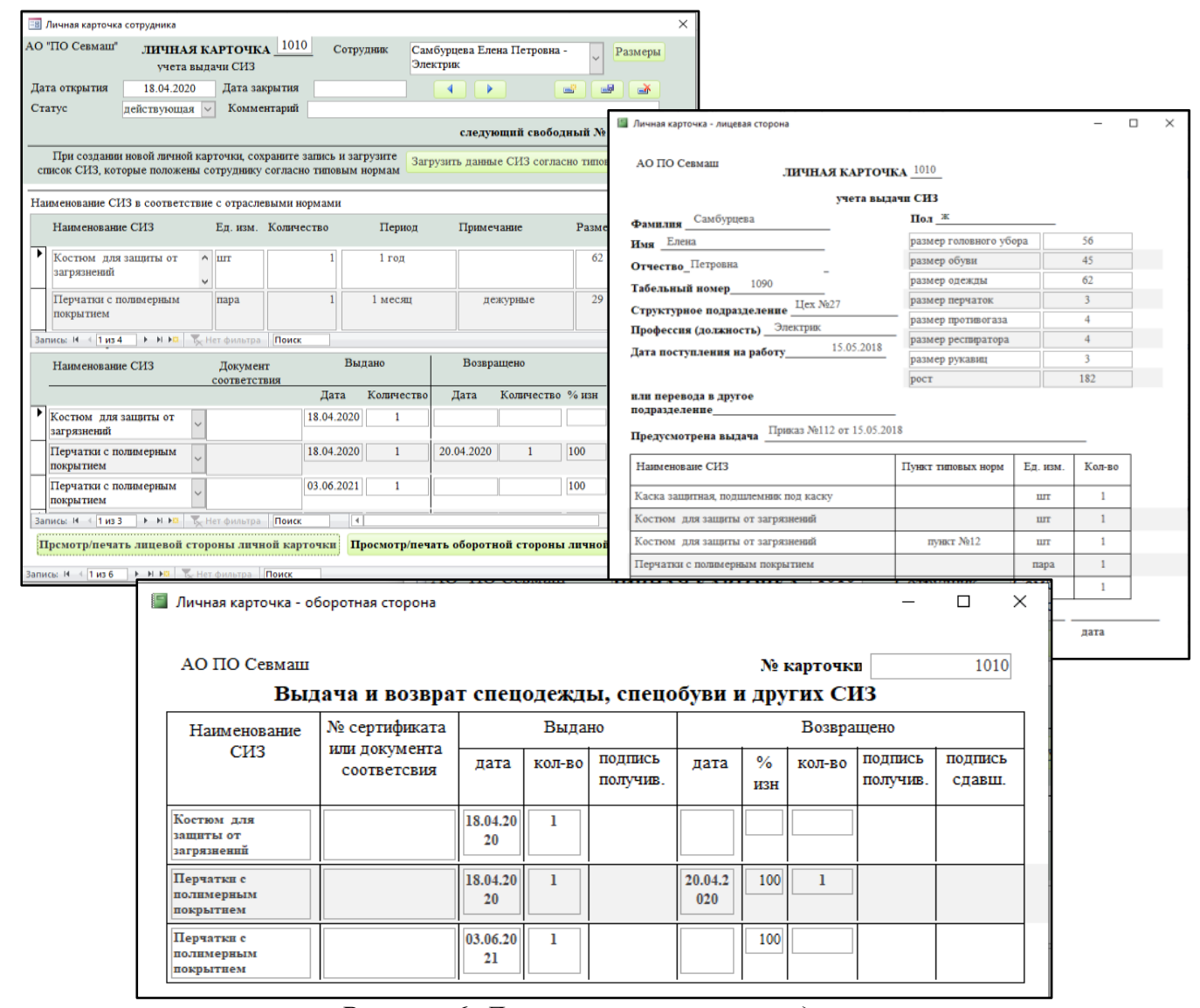

Рисунок 6. Личная карточка сотрудника

Листинг 1

Код загрузки данных СИЗ, положенных по нормам сотрудника, согласно его профессии

Omкpblmb 3 anpoc
NSERT INTO LICH_KARTA_LICEVAY (nazv_siz, ed_izm, kolvo, Period, kod_siz, $\left.n \_l k\right)$
SELECT SIZ.name_siz, ED_IZM.name_kr, NORMI_SIZ.Kol, NORMI_SIZ.Period, SIZ.kod_siz, LICH_KARTA.n_lk
AS Virl
FROM ((PROF INNER JOIN (ED_IZM INNER JOIN (SIZ INNER JOIN NORMI_SIZ ON SIZ.kod_siz =
NORMI_SIZ.kod_siz) ON ED_IZM.kod_ed_izm = SIZ.kod_ed_izm) ON PROF.kod_pr = NORMI_SIZ.kod_prof)


INNER JOIN SOTR ON PROF.kod_pr = SOTR.kod_pr) INNER JOIN LICH_KARTA ON SOTR.id_sotr = LICH_KARTA.id_sotr

WHERE (([LICH_KARTA.n_lk)=[Формы] ![Личная карточка сотрудника]![n_lk]));

ЗапускКомандыМеню

Обновить

Для отражения в системе операций учета поступлений СИЗ в кладовую, и списания пришедших в негодность или с истекшим сроком годности был разработан интерфейс для реализации возможности ведения кладовщиком требований и актов списания.

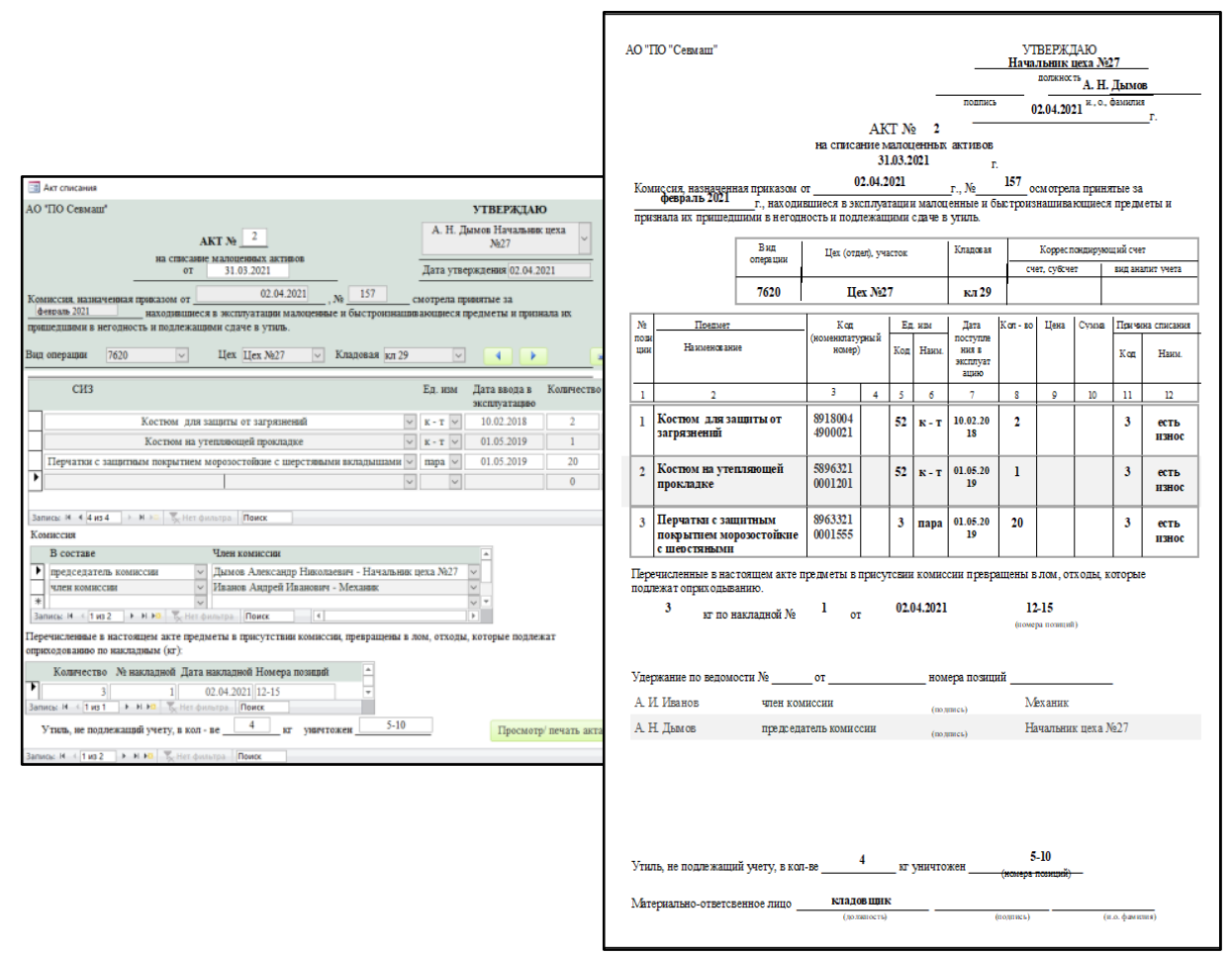

Рисунок 7. Требование на отпуск малоценных активов в эксплуатацию

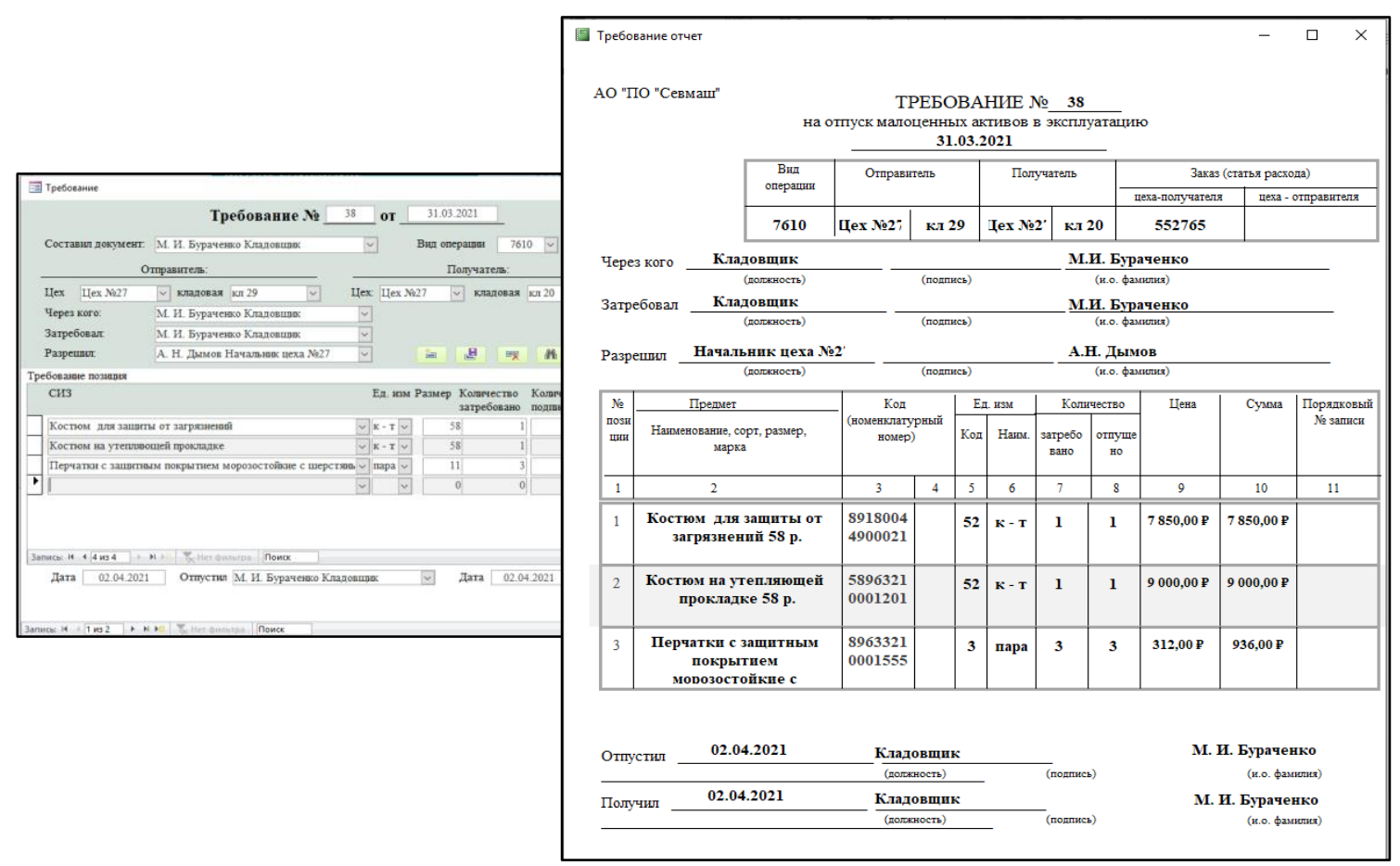

Рисунок 8. Акт списания 
Одним из трудоёмких этапов процесса учёта средств индивидуальной защиты сотрудников предприятия является формирование заявки на получение СИЗ взамен списанных. Разработанный интерфейс позволяет выполнить данную операцию за считанные секунды на основании ранее введенных данных по всем автоматизированным операциям учета.

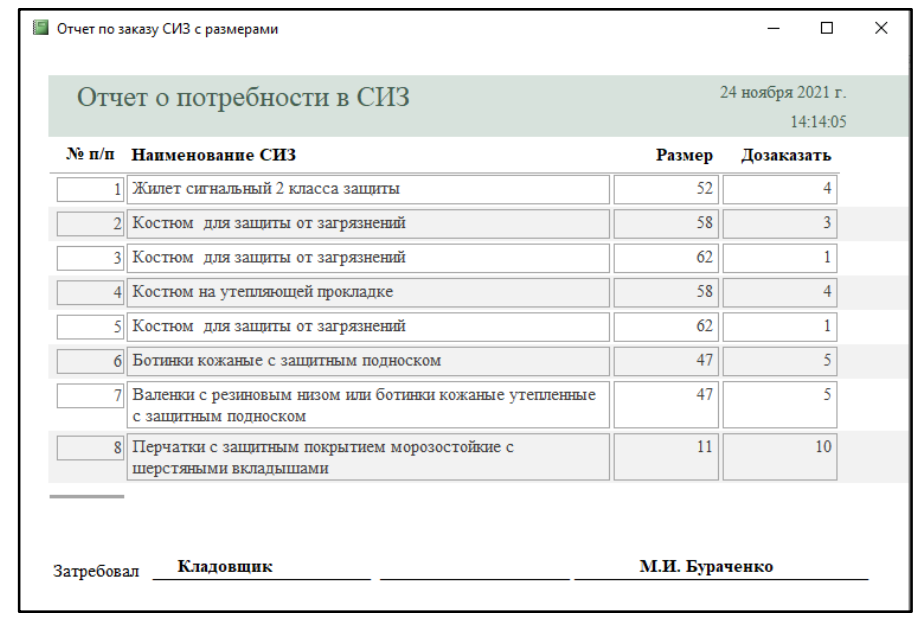

Рисунок 9. Сформированный отчет о потребности в СИЗ на дату формирования отчета

Листинг 2

Код расчета потребности в СИЗ

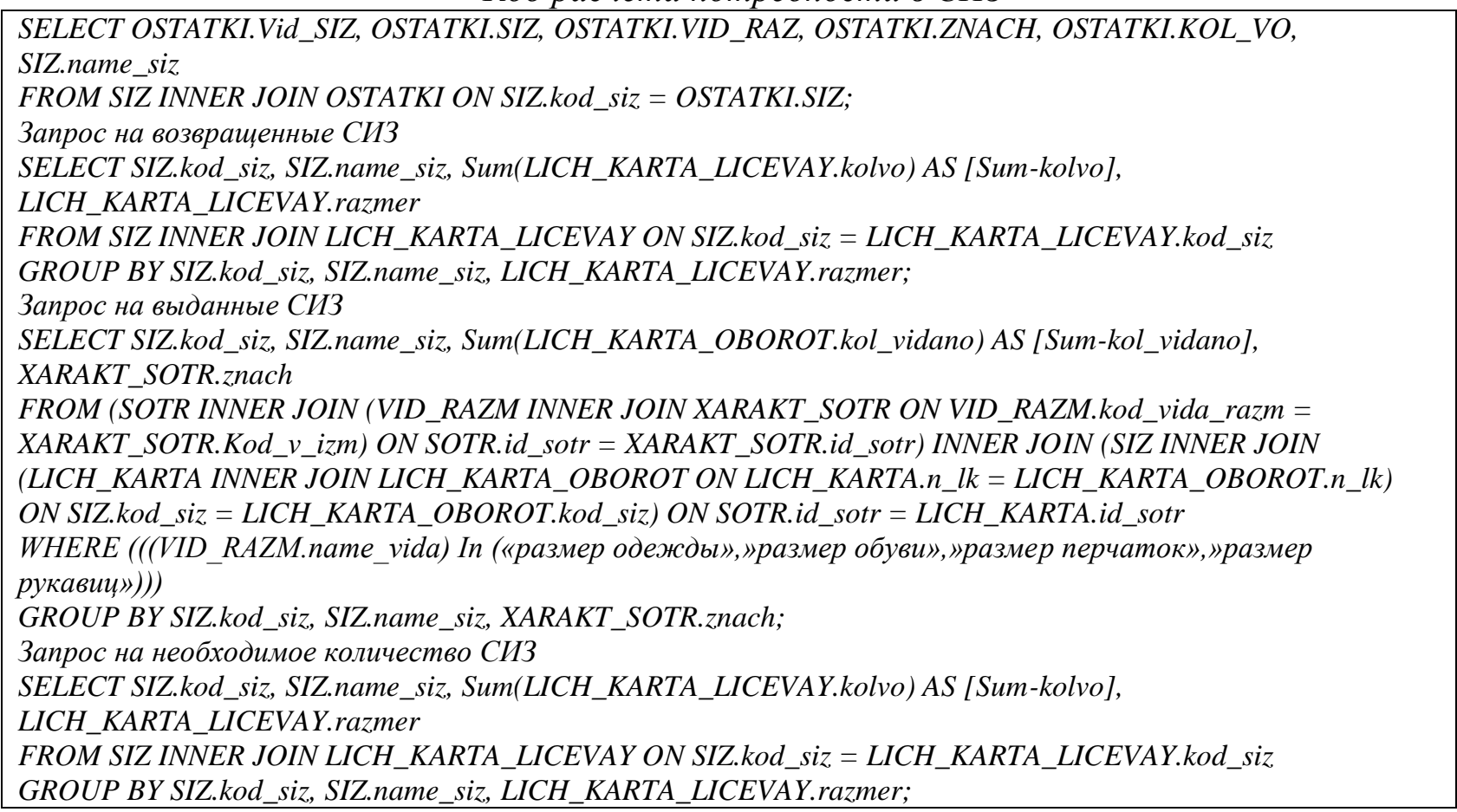

Представленная в данной работе система установлена на рабочем месте кладовщика и проходит стадию рабочего тестирования [1].

$$
* * *
$$

1. ГОСТ 34.601-90. Автоматизированные системы. Стадии создания. [Текст]. - Введ. с 1992-01-01. М.: Стандартинформ, 2009 - 6 с. (Информационная технология. Комплекс стандартов на автоматизированные системы)

2. Приказ Минздравсоцразвития РФ от 01.06.2009 №290Н (редакция от 12.01.2015) «Об утверждении Межотраслевых правил обеспечения работников специальной одеждой, специальной обувью и другими 
средствами индивидуальной защиты» / Контур Норматив [Электронный ресурс] - Режим доступа: https://normativ.kontur.ru/document?moduleId=1\&documentId=233654.

3. Приказ Минтруда России от 09.12.2014 №997Н «Об утверждении Типовых норм бесплатной выдачи специальной одежды, специальной обуви и других средств индивидуальной защиты работникам сквозных профессий и должностей всех видов экономической деятельности, занятым на работах с вредными и (или) опасными условиями труда, а также на работах, выполняемых в особых температурных условиях или связанных с загрязнением» / Контур Норматив [Электронный ресурс] - Режим доступа: https://normativ.kontur.ru/document?moduleId=1\&documentId=247205.

4. РД 5.0496 - 87 ССБТ Средства индивидуальной защиты работающих. Порядок обеспечения, хранения и ухода / Электронный фонд правовых и нормативно - технических документов [Электронный ресурс] Режим доступа: https://docs.cntd.ru/document/1200000277.

\section{Умархаджиев М-X.P. \\ Кибербезопасность: угрозы, вызовы}

ФГБОУ ВО Чеченский государственный университет им А.А.Кадырова

(Россия, Грозныци)

doi: 10.18411/trnio-12-2021-105

\section{Аннотация}

Кибербезопасность - необходимое соображение для информационные технологии, а также интернет-услуги. Нам нужно признать важность различных типов рисков, которые существуют в онлайн-мире. Повышение кибербезопасности и защита критически важной информации имеет важное значение для национальной безопасности и экономическое существо. Всякий раз, когда мы думаем о кибербезопасность мы думаем о «киберпреступности», которая растет день ото дня. Различные правительства и компании принимают меры по предотвращению киберпреступности. Эта статья в основном фокусируется на тенденциях, проблемах и киберэтике в области компьютерная безопасность. Киберинциденты подчеркивают важность быть в курсе мировых тенденций киберпреступности, особенно относительно использования мобильных и персональных вычислительных устройств. Ключевые слова: кибербезопасность, киберинциденты,
киберпреступление, компьютерная безопасность.

\section{Abstract}

Cybersecurity is a necessary consideration for information technology as well as internet services. We need to recognize the importance of the different types of risks that exist in the online world. Enhancing cybersecurity and protecting critical information is essential to national security and economic substance. Whenever we think about cybersecurity we think about "cybercrime", which is growing day by day. Various governments and companies are taking action to prevent cybercrime. This article mainly focuses on trends, issues, and cyber ethics in the field of computer security. Cyber incidents highlight the importance of keeping abreast of global cybercrime trends, especially regarding the use of mobile and personal computing devices.

Keywords: cybersecurity, cyber incidents, cyber ethics, cyber crime, computer security.

Технологии развивались в разные эпохи. Интернет позволил людям отправлять и получать любую форму данных с большей скоростью. Но насколько безопасно данные передаются другому человеку без какой-либо утечки информация? - это один из важны вопросов. Сегодня Интернет - одна из самых быстрорастущих инфраструктур. В сегодняшней технической окружающей среды многие новейшие технологии меняют облик человечества. Заглядывая вперед, ясно одно: сегодня технологии не будут выглядеть так, как они выглядят. Но из-за этих новых технологий мы не можем эффективно защищать нашу личную информацию. Несмотря на технологические меры, принятые организаций и частных лиц, киберпреступность растет день ото дня. Большинство коммерческих сделок происходят 